\title{
Reservoir Pressure of Coal-Bed Methane Prediction Research Based on Analysis Method by Neural Net-work
}

\author{
Xing-peng Jing \\ Xi'an Branch, China Coal Technology and Engineer Group Corp Shaanxi Xi’an , China \\ E-mail:jingxingpeng@163.com
}

\begin{abstract}
In order to achieve accurate quantitative results of parameters for reservoir pressure of coal-bed methane, neural network prediction analytic method is adopted to predict the reservoir pressure of coal-bed methane. The main controlling factors such as conformation Stress, buried depth, in-situ stress and permeability are investigated. Mathematical models of neural network of reservoir pressure of coal-bed methane of mathematical analysis and system architecture are established; taking the Qinshui Basin coal seam as example to forecast and use reservoir pressure of coal-bed methane. Projections show that: the use of neural network prediction of reservoir pressure of coal-bed methane is feasible; neural network method makes up a mathematical point of linear and regularity in order to solve the non-linear complex relationship between the input and output parameter variables.
\end{abstract}

Keywords-coal-bed methane, reservoir pressure, neural network, net-work structure, mathematical model

\section{INTRODUCTION}

Coal-bed methane is mainly composed of methane $\left(\mathrm{CH}_{4}\right)$. The adsorption state occurs in the sedimentary basins of the coal seam. The symbiotic energy with coal mining is also known as coal-bed methane or coal gas. The reservoir parameters tested about China's coal bed methane (also known as coal gas) mainly include reservoir pressure, reservoir permeability of coal-bed methane, the survey radius, skin factor and in-situ stress, etc.The reservoir pressure of coal-bed methane is one of the most important parameters, which refers to seam pore fluid (including gas and water) pressure. And it controls directly the gas content of the coal reservoir adsorption gas (gas saturation), and it has a direct impact on the process of CBM Drainage in the mining process. Reservoir pressure plays an important role for coal-bed methane content and gas occurrence. At the same time, the reservoir pressure was energy and momentum for water and gas flowing from the fissures of the coal to the well-bore. Therefore research on reservoir pressure is important for coal-bed methane production. The CBM reservoir pressure evaluation is the basic parameter for exploration, evaluation and development of coal-bed methane (coal gas), also serves as the main evaluation of coal mine gas data. ${ }^{[1-5]}$

\section{MAIN FACTORS THAT AFFECT RESERVOIR PRESSURE OF COAL-BED METHANE}

There are many factors affecting the coal-bed methane reservoir pressure including conformation stress, buried depth, in-situ stress, permeability, operating processing and other factors. These factors not only affect the occurrence characteristics of coal-bed methane also affect the accuracy of test results about the reservoir pressure of coal-bed methane.

(1)Conformation stress factors. Geological structure not only influence and control the coal-bed methane buried, distribution, and closed conditions, but also create a direct impact on the role of fluid pressure in the reservoir pore space of coal-bed methane. Conformation stress makes formation pore volume become smaller and reservoir pressure increase. So pressure distribution changes is clearly different in different structural form of CBM reservoirs such as the syncline, anticline or monoclinic structure for the coal-bearing area, and coal-bed methane reservoir burial, closed conditions and coal-bed methane reservoir are also different respectively.

(2)Seam buried depth factor. Seam buried depth factor have different impact on reservoir pressure of coal-bed methane. Through the analysis and comparison about the test results of different coal mines in china, the results show that it has a large deviation on the reservoir pressure even in the same coal seam. According to the results of the test, the reservoir pressure of CBM increases as seam depth increases.

(3) In-situ stress. The rule existing between reservoir pressure and in-situ stress is contradicted to exploitation of $\mathrm{CBM}$. When reservoir pressure is comparatively larger, it is easy for drainage to create fall-off leading differencepressure so as coal-bed methane can easily desorb from coal seams. In-situ stress has a negative effect on exploitation of CBM. In-situ stress plays closure for hole of coal seam that in-situ stress is larger and pore open degree is smaller in order to affect fluid seepage channel for coal-bed methane and reduce the reservoir permeability of coal-bed methane, so it affects the production of coal-bed methane. Forasmuch exploration of CBM is always selected in small in-situ stress and high reservoir pressure high area to explore and develop.

(4) Reservoir permeability of coal-bed methane. Coal-bed methane reservoir has undeveloped cracks serious filling and poor hydraulic connection that does not have the pressure on a large area of water development conditions. It is lost large of CBM and lack of hydro energy supplement. So the size of the permeability will affect the reservoir pressure $^{[1-3]}$.

\section{NEURAL NETWORKS}

Neural network is a computing system which is consist of multiply processing units. These units connect with each other by some method. The system processes information by its state responding to outside information. It is put 
forward on the basis of modern neural science research achievement, shows human brain's basic traits and serves as an important method to imitating artificial intelligence. Neural net is a huge system containing multiply neurons which composite by some rules. Nodes in the net could be divided into two parts: one is input node with responsibility of introducing outside information and delivering it to the first hidden layer; the other is processing-capable node, including hidden layer node and output layer node. Standard neural net's topological structure is constituted by three layers: input layer in far left, hidden layer in middle, output layer in far right. The amount of input layer and output layer can be decided by the requested problems, while the amounts of middle layer neurons surly need discussion. Neurons from different layers develop a full interconnection connection and neurons from the same layers do not connect with each other. Neural net with three layers is able to imitate the complicated Nonlinear mapping relation between input and output. According to the directions of information delivery in neural net, the net can be divided into feed forward neural networks and feedback neural networks. In feed forward neural networks, a layer's output servers as the next layer's input and the information processing shows the directivity by transferring information layer by layer. In general there is no feedback loop. Every node in feedback net is able to process information and not only can it receive outside information but also output information. The learning process adopted by neural net concludes forward and backward propagating. So, the essence of neural network method lies in valuating error function's minium. By repeated study of multiply samples, the connection weights and neuron offset value of each layer from the study of several known samples are saved to predict the untouched samples' values and then the predicted result is computed ${ }^{[3-}$ 8].

\section{RESEARCH OF RESERVOIR PRESSURE PREDICTION BY NEURAL NETWORKS}

The application of neural network technique in coal seam and gas reservoir pressure prediction is to imitate the complicated nonlinear relationship in coal-bed methane field. In the essence, neural network training problem is a function minimization problem, but its foundation of mathematics is nonlinear theory. For the system's advanced nonlinear, BP algorithm has the problems of low efficiency, slow convergence and it is easy to fall into local minimum, which restricts the application of neural network in complicated system. Most of new research focus on the improvement of algorithm, such as conjugate gradient algorithm, algorithm Based on the information entropy optimization and modified BP. The application of neural network has been developed through this research ${ }^{[6-8]}$.

\section{A. The reservoir pressure prediction System flow diagram of the neural net-work}

Neural network is constituted by a great number of processing units which are similar to neurons connecting with each other to be a complicated nonlinear network. It imitates human brain's neurons to process, memorize and identify etc, to fulfill human brain's information processing function, which serves as a show of Cyborg Sensation. Only by study algorithm, can neutral network model imitate the given inter-physical volume. The neutral network system flow chat is shown in figure-1. Firstly, we set the initialized neutral network and given study model and then start the training, compare the computed output result and expected result. If the deviation is small, we should compute the neutral network output, or we continue the training to make it within the deviation range. That is when the network is studying, we should provide a set of input samples in which every sample is constituted of input and target output. If the provided samples are enough and strongly representative, network will find the nonlinear relationship between controlling factors and evaluation index by self-organizing and adapting ability. The sample order is divided into study set and text set. Study set is mainly used to study training, make the network adjust structure function and parameter by study of algorithm until the predicted value meets the requirements, while text set is used to evaluate whether the performance of network, which has been studied, can be related to nonlinear function or not. Finally, the most satisfying predicted model and predicted value will be achieved.

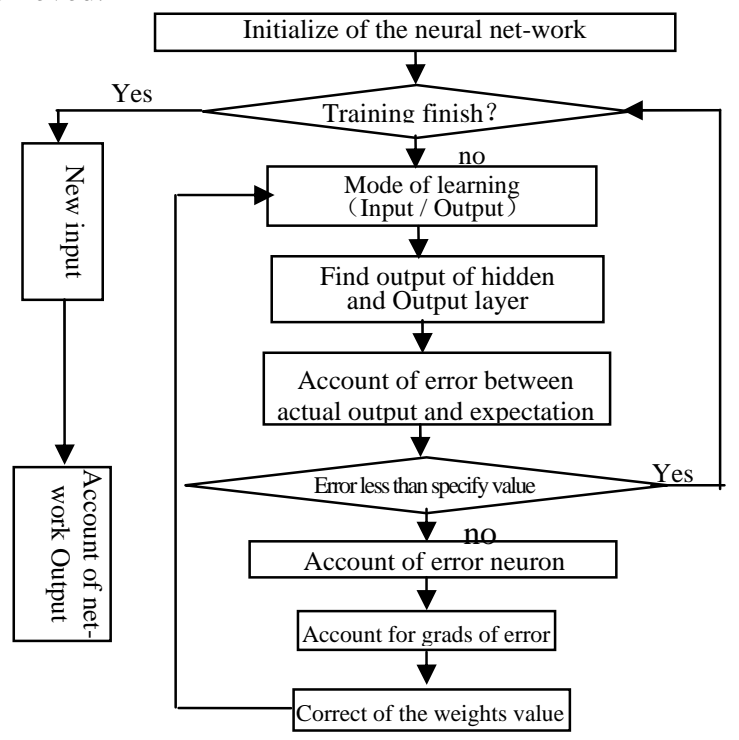

Figure 1. System flow diagram of the neural net-work

\section{B. The reservoir pressure prediction system step of the neural network}

(1)Establish sample data. The primary and premise condition to modeling by neutral network is to collect enough samples with good typicality and high precision. Besides, in order to supervise the training (study) process to avoid the "over-fitting" state and evaluate the established network model's performance and generalization ability, the collected data must be separated randomly into three parts: training sample, examining sample (more than 10\%) and test sample (more than 10\%). Study and training samples are the most representative text samples collected from the 
mining test in coal-bed methane field over the years, whose input parameter is based on the influential factors of coalbed methane reservoir pressure. According to these factors, there are many influential factors of coal-bed methane reservoir pressure. According to the above analysis, we chose effective burial depth of coal seam, n-situ stress, coal structure and permeability the top four controlling factors as the basic factors in coal-bed methane reservoir pressure prediction to predict the coal-bed methane reservoir pressure. (2)Determine the network structure. Based on the gas factors we determined 4 input layers. For the hidden neural network layer, only some empirical formula could be adopted to determine its' number. According the studies when input layer has $\mathrm{N}$ nodes the hidden layer should has $2 \mathrm{~N}+1$ nodes, only in this way the gotten prediction result could reflect the real condition and ensure the accuracy of neural network computing. In fact, the hidden layer's node is not fixed but adjusted through learning. Based on the above analysis, the gas prediction model adopts 4 input layers, so there are 9 hidden layers. Finally, we determined a 4-9-1neural network, and the specific network was shown in figure2.

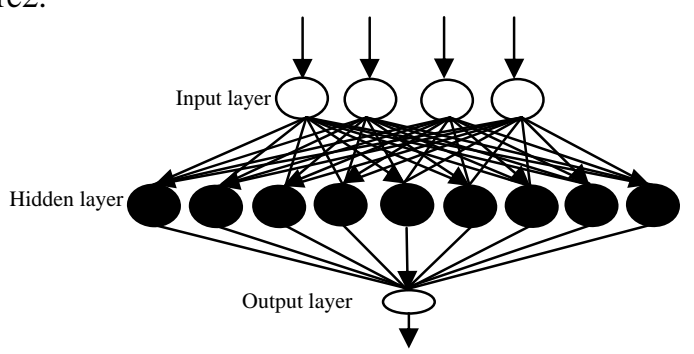

Figure 2. The reservoir pressure of neural net-work structure

(3)Train the neutral network. The training of neural network is to adjust the network weights under the error back propagation principle to make sure the the error sum of squares between network model output value and known training samples output value reach the minimum or within an expectation value. Now, experience knowledge and designer's experience are most needed to a large scale in nowadays. Therefore, establishing a proper neutral network model by studying(training) the training samples is regarded as "the process of artistic creation" in foreign countries, which is a very complicated and difficult process loaded with trivial details.

(4) Decide the neutral network's weights and threshold value. Neutral network algorithm determines that there always exists (many) multiply local minimum points in error function. And different network initialized weights and threshold values decide to which local minimum point or global minimum point the neutral network algorithm will be converged. So, the calculator program (at this stage, we generally adopt standard universal softwares, such as Statistica Neural Networks by Statsoft and Matlab) must be able to change network initialized weights and threshold value freely.

(5) Identify and output coal-bed methane reservoir pressure neural network. The process of neutral network modeling is a process of continuous adjustment and contrasting results, which is complicated and attached with experiment. The process is never like some authors' imaginations (they actually do this): To form a formula to determine the number of hidden layer nodes and establish the proper network model by one training (the model established in this way probably responds to the error of training sample and it is of no practical use); therefore, multiply neutral network training must be done by sample data to compute and predict more proper and reliable coalbed methane reservoir pressure predicted value.

\section{Analysis the neural network reservoir pressure prediction result}

Regard the gas samples as the known samples to learn and train. The learning and training samples of reservoir pressure of coal-bed methane are shown in table1, where effectively buried depth of coal seam, in-situ stress, coal structure and permeability as 4 the mainly controlling factors, and the output factor is the prediction result of reservoir pressure. And with 40 prediction results and actual test values' comparison we learn and train samples, among the results there are 34 dates as learning and training, 6 dates as the test samples.

The 40 comparison results show that the accuracy of reservoir pressure by neural network is very high. The error between the prediction and actual test is very small. The accuracy is as high as $90 \%$. According to the learning and training samples of reservoir pressure and the 6 known samples $(11,12,19,20,33$,and 33$)$ as the test samples which based on the neural network, at the certain learning conditions the error of prediction results and actual test results is very small. We set the actual tested results as the learning and training samples, and find that the accuracy of the gas prediction based on the neural network model is generally greater than $90 \%$ (the error is $\pm 10 \%$ ). Therefore, we can get the conclusion that the prediction result based on neural network is steady and reliable.

\section{CONCLUSIONS}

(1)Although there are so many factors for reservoir pressure of coal-bed methane, we can accord to the characters of coal seam itself and through the comprehensive analysis of the factors in order to get the main controlling reservoir pressure of coal-bed methane factors. They are effectively buried depth of coal seam, insitu stress, coal structure and permeability.

(2)Because there is a comprehensive non-linear relationship between the reservoir pressure factors, even some of them are random, vague and in short term, so it is hard to process the date by traditional mathematical method theory.

(3)The neural model of reservoir pressure of coal-bed methane is a network structure which is based on the 4 factors that are effectively buried depth of coal seam, in-situ stress, coal structure, permeability and 1 output parameter: 4-9-1model. The error of used neural network to predict the reservoir pressure of coal-bed methane is small, usually the 
accuracy is greater than $90 \%$. Therefore, the neural network can be promoted in predicting the reservoir pressure's usage.

\section{REFERENCES}

[1] Jing Xingpeng. Researching of gas pressure distribution law in south coalbed of Qin Shui basin[D].Xi'an:Xi'an university of science and technology,2010:1-16

[2] Yu Bufan. Manuals of coal mine gas disaster prevention and the gas use technical [M].Bei Jing: Coal Industry Press.2005:1-38

[3] Jing Xingpeng. Study on Pressure Distribution Law and Control Factors of Coal Bed Methane Reservoir in South Part of Qinshui Basin[J].Coal Science and Technology,2012,40(2): 116-120,124.
[4] Qian Kai, Zhao Qingbo, Wang Zecheng.The theoretical and experimental testing technology of coal bed methane's esploration and development[M].Bei Jing:Petroleum Industry Press.1997:1-15

[5] GB/T24504-2009, The injection/falloff well-test method for CBM well [S]. Bei Jing:Standards Press of China.2008

[6] Zhou Zhihua,Cao Cungen. The application of neural network[M].Bei Jing:Tsinghua University Press.200:1-56.

[7] Hao Ji sheng; YUAN Chong fu. The applying of fuzzy network techniques in prediction of coal and gas outbursts[J]. Journal of china coal society,1999,24(6):624-627

[8] Shi Hongbao. The application of neural network[M].Xi'an:Xi'an Jiaotong University Press.1987:1-79

TABLE I. THE STATISTICS OF NEURAL NETWORK PREDICTION LEARNING SAMPLES AND PREDICTION RESULTS

\begin{tabular}{|c|c|c|c|c|c|c|c|c|}
\hline $\begin{array}{c}\text { Sample } \\
\text { number }\end{array}$ & $\begin{array}{l}\text { effective buried depth } \\
\text { of coal seam } / \mathrm{m}\end{array}$ & coal structure & $\begin{array}{c}\text { in-situ stress } \\
/ \mathrm{MPa}\end{array}$ & $\begin{array}{c}\text { permeability } \\
\text { / md }\end{array}$ & $\mathbf{P}_{\mathbf{y c}}$ & $\mathbf{P}_{\text {sc }}$ & $\mathbf{P}_{\mathrm{yc}}-\mathbf{P}_{\mathrm{sc}}$ & accuracy/\% \\
\hline 1 & 209.05 & columnar & 7.62 & 0.47 & 1.87 & 1.70 & 0.17 & 90.00 \\
\hline 2 & 301.55 & columnar & 4.36 & 8.92 & 2.54 & 2.66 & -0.12 & 95.49 \\
\hline 3 & 336.85 & massive & 9.69 & 0.18 & 0.88 & 0.76 & 0.12 & 84.21 \\
\hline 4 & 438.86 & columnar & 19.21 & 0.06 & 1.20 & 1.13 & 0.07 & 93.81 \\
\hline 5 & 433.20 & columnar & 6.42 & 0.23 & 0.74 & 0.67 & 0.07 & 89.55 \\
\hline 6 & 522.55 & columnar & 6.11 & 11.28 & 1.68 & 1.56 & 0.12 & 92.31 \\
\hline 7 & 418.30 & short column & 5.62 & 1.08 & 1.17 & 1.28 & -0.11 & 91.41 \\
\hline 8 & 499.65 & massive & 7.28 & 10.51 & 1.26 & 1.21 & 0.05 & 95.87 \\
\hline 9 & 413.91 & columnar & 9.44 & 6.49 & 1.72 & 1.67 & 0.05 & 97.01 \\
\hline 10 & 506.43 & columnar & 10.92 & 21.01 & 2.65 & 2.54 & 0.11 & 95.67 \\
\hline $11 \hat{\jmath}$ & 476.87 & massive & 9.69 & 0.03 & 1.62 & 1.38 & 0.24 & 82.61 \\
\hline $12 々$ & 567.02 & columnar & 11.17 & 0.14 & 3.20 & 3.34 & -0.14 & 95.81 \\
\hline 13 & 649.15 & columnar & 9.31 & 2.93 & 5.81 & 5.73 & 0.08 & 98.60 \\
\hline 14 & 922.34 & columnar & 10.57 & 0.05 & 8.41 & 8.22 & 0.19 & 97.69 \\
\hline 15 & 661.56 & columnar & 16.88 & 0.03 & 3.80 & 3.58 & 0.22 & 93.85 \\
\hline 16 & 736.54 & long column & 18.79 & 0.12 & 4.01 & 3.86 & 0.15 & 96.11 \\
\hline 17 & 555.20 & columnar & 9.42 & 0.03 & 2.90 & 3.04 & -0.14 & 95.39 \\
\hline 18 & 641.73 & columnar & 16.05 & 0.04 & 4.60 & 4.48 & 0.12 & 97.32 \\
\hline $19 \lesssim$ & 539.12 & columnar & 16.74 & 0.04 & 1.69 & 1.55 & 0.14 & 90.97 \\
\hline $20 \lesssim$ & 534.34 & massive & 9.12 & 0.07 & 3.27 & 3.02 & 0.25 & 91.72 \\
\hline 21 & 617.23 & columnar & 10.06 & 0.02 & 2.94 & 3.63 & -0.69 & 80.99 \\
\hline 22 & 373.45 & massive & 8.24 & 11.53 & 1.61 & 1.52 & 0.09 & 94.08 \\
\hline 23 & 471.91 & columnar & 6.88 & 21.32 & 2.70 & 2.28 & 0.42 & 81.58 \\
\hline 24 & 247.05 & columnar & 7.81 & 1.84 & 1.70 & 1.37 & 0.33 & 75.91 \\
\hline 25 & 341.20 & columnar & 9.42 & 0.61 & 1.88 & 2.04 & -0.16 & 92.16 \\
\hline 26 & 721.13 & columnar & 13.84 & 0.02 & 6.14 & 5.81 & 0.33 & 94.32 \\
\hline 27 & 415.21 & massive & 6.39 & 32.11 & 0.29 & 0.31 & -0.02 & 93.55 \\
\hline 28 & 376.95 & massive & 8.39 & 10.05 & 0.21 & 0.16 & 0.05 & 68.75 \\
\hline 29 & 545.71 & massive & 8.42 & 0.39 & 1.83 & 1.60 & 0.23 & 85.63 \\
\hline 30 & 644.42 & columnar & 13.25 & 0.12 & 2.47 & 2.56 & -0.09 & 96.48 \\
\hline 31 & 591.45 & fragment & 11.61 & 2.09 & 1.80 & 1.71 & 0.09 & 94.74 \\
\hline 32 & 645.81 & columnar & 14.90 & 1.97 & 2.24 & 2.11 & 0.13 & 93.84 \\
\hline $33 \preccurlyeq$ & 741.91 & columnar & 15.42 & 0.02 & 4.21 & 4.01 & 0.20 & 95.01 \\
\hline $34 \lesssim$ & 641.90 & columnar & 6.92 & 0.10 & 0.67 & 0.68 & -0.01 & 98.53 \\
\hline 35 & 634.71 & massive & 12.67 & 0.43 & 3.06 & 2.50 & 0.56 & 77.60 \\
\hline 36 & 651.90 & columnar & 7.43 & 4.97 & 2.73 & 2.47 & 0.26 & 89.47 \\
\hline 37 & 478.67 & massive & 10.63 & 2.21 & 1.80 & 1.67 & 0.13 & 92.22 \\
\hline 38 & 653.20 & columnar & 8.04 & 0.12 & 3.41 & 3.12 & 0.29 & 90.71 \\
\hline 39 & 414.53 & Broken kernel & 8.48 & 1.18 & 3.54 & 3.72 & -0.18 & 95.16 \\
\hline 40 & 348.80 & columnar & 7.94 & 1.10 & 1.50 & 1.43 & 0.07 & 95.10 \\
\hline
\end{tabular}

In the table, Pyc—-the prediction of reservoir pressure/MPa, Psc—actual tested value/MPa accuracy=[1-( $\left.\left(G_{y y}-G_{s c}\right) / G_{s c}\right] 100 \%$, is—test samples 